\title{
The hybrid non-ethylene and ethylene ripening response in kiwifruit (Actinidia chinensis) is associated with differential regulation of MADS-box transcription factors
}

Peter A. McAtee ${ }^{1,2}$, Annette C. Richardson ${ }^{3}$, Niels J. Nieuwenhuizen ${ }^{1,2}$, Kularajathevan Gunaseelan ', Ling Hoong ${ }^{1,2}$, Xiuyin Chen ${ }^{1}$, Ross G. Atkinson ${ }^{1}$, Jeremy N. Burdon ${ }^{1}$, Karine M. David ${ }^{2}$ and Robert J. Schaffer ${ }^{1,2^{*}}$

\begin{abstract}
Background: Ripening in tomato is predominantly controlled by ethylene, whilst in fruit such as grape, it is predominantly controlled by other hormones. The ripening response of many kiwifruit (Actinidia) species is atypical. The majority of ripening-associated fruit starch hydrolysis, colour change and softening occurs in the apparent absence of ethylene production (Phase 1 ripening) whilst Phase 2 ripening requires autocatalytic ethylene production and is associated with further softening and an increase in aroma volatiles.

Results: To dissect the ripening response in the yellow-fleshed kiwifruit A. chinensis ('Hort16A'), a two dimensional developmental stage $X$ ethylene response time study was undertaken. As fruit progressed through maturation and Phase 1 ripening, fruit were treated with different concentrations of propylene and ethylene. At the start of Phase 1 ripening, treated fruit responded to ethylene, and were capable of producing endogenous ethylene. As the fruit progressed through Phase 1 ripening, the fruit became less responsive to ethylene and endogeneous ethylene production was partially repressed. Towards the end of Phase 1 ripening the fruit were again able to produce high levels of ethylene. Progression through Phase 1 ripening coincided with a developmental increase in the expression of the ethylene-unresponsive MADS-box FRUITFUL-like gene (FUL1). The ability to respond to ethylene however coincided with a change in expression of another MADS-box gene SEPALLATA4/RIPENING INHIBITOR-like (SEP4/RIN). The promoter of SEP4/RIN was shown to be transactivated by EIN3-like transcription factors, but unlike tomato, not by SEP4/RIN itself. Transient over-expression of SEP4/RIN in kiwifruit caused an increase in ethylene production.

Conclusions: These results suggest that the non-ethylene/ethylene ripening response observed in kiwifruit is a hybrid of both the tomato and grape ripening progression, with Phase 1 being akin to the RIN/ethylene inhibitory response observed in grape and Phase 2 akin to the $R / N$-associated autocatalytic ethylene response observed in tomato.
\end{abstract}

Keywords: Actinidia, Fruit Ripening, Ethylene, Ripening Inhibitor

\footnotetext{
* Correspondence: robert.schaffer@plantandfood.co.nz

${ }^{1}$ The New Zealand Institute for Plant \& Food Research Limited (PFR), Mt

Albert Research Centre, Auckland, New Zealand

${ }^{2}$ School of Biological Sciences, University of Auckland, Auckland, New

Zealand

Full list of author information is available at the end of the article
} 


\section{Background}

In all fleshy fruits, fruit maturation and ripening is achieved through complex metabolic processes that are regulated by both developmental and hormonal factors. While hormones such as auxin, abscisic acid and cytokinins have all been linked to the ripening process [1], the best characterised hormone is ethylene, due to its extreme ripening effect in many fruit. Ethylene is synthesised in a simple three-step pathway from methionine, through S-ADENOSYL METHIONINE SYNTHETASE (SAM), 1-AMINO CYCLOPROPANE-1-CARBOXYLATE SYNTHASE (ACS) and ACC OXIDASE (ACO) [2]. All these genes are associated with multi-gene families, and in many plants $A C S$ has been shown to be a ratelimiting step for ethylene biosynthesis [2]. The ACS gene family consist of three classes of genes, depending on the presence of destabilisation elements in the carboxy (C) termini [3] that are regulated by the F-box genes ETHYLENE OVER PRODUCER (ETO) [4]. In fruit with autocatalytic ethylene-associated ripening, specific members of each of these biosynthetic gene-families are associated with ripening, which, when suppressed result in a loss or reduction in ripening is observed [5-8].

Fruit perceive ethylene through a multi-step signalling pathway that begins with the binding of ethylene to a twocomponent transmembrane receptor complex found at the endoplasmic reticulum [9-12]. Multiple ethylene receptor and ethylene sensor complexes have been identified in tomato and Arabidopsis that have also been shown to bind ethylene. The binding of ethylene to these receptors suppresses a mostly linear pathway that ultimately leads to the stabilisation of the EIN3 family of transcription factors which regulate ethylene-responsive genes, reviewed [13]. Transcription factors such as the SQUAMOSA BINDING PROTEIN (SQBP), COLOURLESS NON RIPENING (CNR) [14], ETHYLENE RESPONSE FACTORS (ERF), as well as various MADS-box genes regulate downstream ripening genes $[15,16]$. In tomato, strawberry, apple, banana and grape, maturation and pre-ethylene ripening events have also been associated with the MADS-box transcription factor class of genes linked to floral organ identity. These include the SEPALLATA (SEP)-like RIPENING INHIBITOR (RIN) [17-20], FRUITFUL (FUL)-like TDR4 [21] and the AGAMOUS (AG)-like TAGL1 [22-24], which interact with one another to switch on ripening-associated genes such as those involved in ethylene biosynthesis [25-29].

Ripening of yellow-fleshed Actinidia chinensis 'Hort16A' fruit is a complex and a highly co-ordinated process that involves changes in flesh texture [30] and colour [31], conversion of starch to soluble carbohydrates $[32,33]$ and the development of taste and aroma compounds [34, 35]. A major ripening change in Actinidia spp. is textural, from a firm texture ( $>50$ Newton $(\mathrm{N})$ firmness) to a soft melting texture (<10 N firmness). The softening of kiwifruit to eating ripeness (6-8 $\mathrm{N}$ firmness) occurs largely in the absence of any detectable ethylene [33, 36, 37], although firm fruit may be extremely responsive to exogenously applied ethylene [32]. This capacity to respond to ethylene develops progressively in the fruit whilst on the vine [32, 38]. When mapped to the phenological Biologische Bundesanstalt, Bundessortenamt und $\mathrm{CHemische}$ Industrie $(\mathrm{BBCH})$ development scale [33], the initial phase of ripening (BBCH 80-89) occurs in the apparent absence of ethylene production (Phase 1). This is similar to the progression of ripening observed in 'non-climacteric' fruit such as grape. However, although no ethylene production is detected during Phase 1 ripening, the ethylene inhibitor 1-Methylcyclopropene (1-MCP) can delay the rapid softening effect, suggesting a response to basal ethylene levels in the fruit [39]. Once the fruit are soft $(<10 \mathrm{~N})$, there is a second ripening phase (Phase 2) in which autocatalytic ethylene production is associated with significant increases in volatile ester and terpene synthesis [34, 35] and senescence (BBCH 90-92) [33]. Hence, even though kiwifruit are largely referred to as an autocatalytic ethylene responsive fruit (climacteric) [40, 41], physiological evidence shows that kiwifruit behave differently from a typical climacteric fruit, such as avocado, banana or tomato. Instead, it should be considered towards one end of a non-climacteric - climacteric continuum, where ethylene production occurs at the end of the ripening process.

Genomic technologies such as Expressed Sequence Tag (EST) sequencing [42], molecular maps [43] and transformation protocols [44] have greatly assisted in understanding of Actinidia species at the molecular level. A number of studies have identified individual members of the ripening-associated ethylene biosynthetic genes $A C O$, $A C S$ and $S A M$ synthase $[8,45,46]$, and ethylene signalling components, including CONSTITUTIVE TRIPLE RESPONSE (CTR), ETHYLENE RESPONSE SENSOR (ERS) and ETHYLENE RESPONSE 1 (ETR1)-like genes [47]. In this study, we utilised genomic information from A.chinensis 'Hongyang' [48] to identify ethylene-related genes and known controllers of fruit ripening, and investigated their expression at key time points over fruit maturation and ripening, to better understand the unusual ripening process observed in kiwifruit.

\section{Results}

Characterisation of maturation and ethylene responses in A. chinensis

A two dimensional developmental stage $\mathrm{X}$ ethylene response time study of $A$. chinensis 'Hort16A' fruit was conducted by sequentially harvesting fruit at weekly intervals from 140 days after full bloom (DAFB) to 231 DAFB (Fig. 1). This time frame was chosen to cover kiwifruit maturation and Phase 1 ripening as described previously by Richardson et al. [33] from a mature fruit 


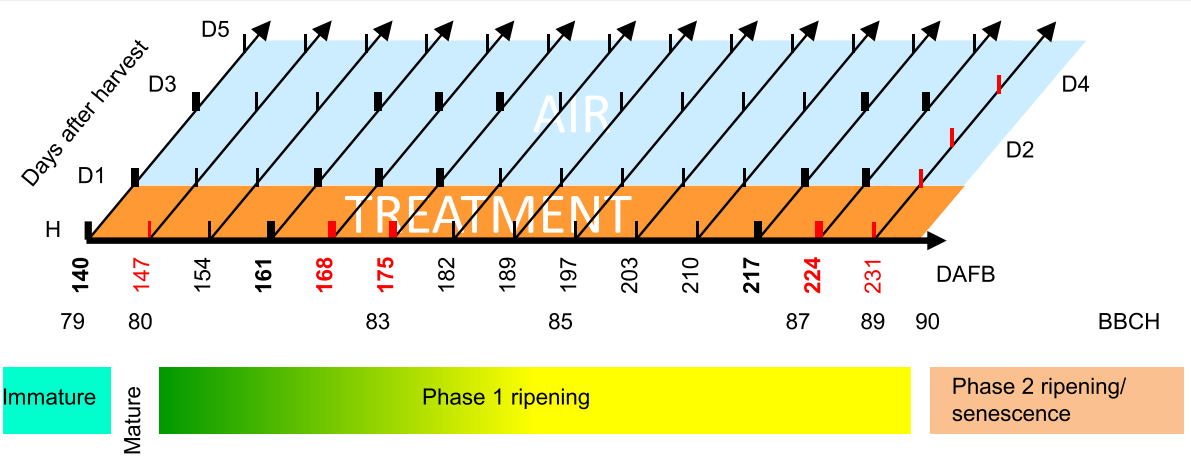

Fig. 1 Two dimensional developmental stage X response time schema. Developmental stage/Dimension 1: Fruit were harvested weekly from 140 to 224 days after full bloom (DAFB). Fruit were assessed for a range of physiological parameters immediately at harvest (H). Developmental stage is given using the $\mathrm{BBCH}$ stage described in [33]. Immature fruit (BBCH 79) contained $80 \%$ black seeds, and $100 \%$ at $\mathrm{BBCH} 80$ and all following stages. Phase 1 ripening (BBCH 80-89) occurs in the apparent absence of ethylene production. Phase 2 ripening (BBCH 90-92) is associated with autocatalytic ethylene production, volatile ester and terpene synthesis and senescence. Response time/Dimension 2: After harvest, fruit were treated with either propylene, ethylene or stored in air for $24 \mathrm{~h}$. Fruit were then transferred to air and assessed for a range of physiological parameters at the points indicated by vertical bars between 1 and 5 days after harvest (DAH). Tissues selected for a mRNA-seq screen are indicated with a red text/bar and those selected for GPCR with a bold text/bar

at stage 79 on the $\mathrm{BBCH}$ scale ( $80 \%$ black seeds) to fruit undergoing on-vine softening at stage 89 (30 N firmness). Each week, a batch of 20 fruit was assessed at harvest $(\mathrm{H})$ for physiological attributes such as soluble sugar content (SSC), outer pericarp colour, firmness, and ethylene emission (Fig. 2). Each week, four batches of 20 fruit were also treated with one of three concentrations of the ethylene analogue propylene (low-100; medium1000 and high-10,000 $\left.\mu \mathrm{L} \cdot \mathrm{L}^{-1}\right)$ and ethylene $\left(100 \mu \mathrm{L} . \mathrm{L}^{-1}\right)$, for 1 day and then transferred into air. As a control, 20 fruit were left untreated. Physiological attributes of treated and untreated fruit were assessed 1, 3 and 5 days after harvest (Figs. 2, 3 and Additional file 1).

Fruit harvested over the 14-week period showed a well documented progression of ripening, with fully black seed observed at 147 DAFB (BBCH 80, as described in [33]). Flesh colour change from a green hue angle $\left(116^{\circ}\right)$ to yellow $\left(100^{\circ}\right)$ started at $168 \mathrm{DAFB}$, with the majority of colour change occurring by 182 DAFB (Fig. 2c). Soluble sugars started increasing at 175 DAFB $(\mathrm{BBCH} 83$; Fig. 2a), while the start of softening occurred at 203 DAFB, and rapidly increased at 224 DAFB (BBCH 87; Fig. 2b). During the experiment no detectable endogenous ethylene production was measured (Fig. 2d). At each time point, for each of these attributes, fruit kept for 5 days in air (with no ethylene or propylene) at ambient temperatures showed little further ripening progression from fruit measured at harvest (Fig. 2).

When treated with propylene or ethylene, at 140 DAFB, all treatments induced a small increase in SSC 5 days after harvest, from $4.5 \%$ to $8 \%$ (Fig. 3a, Additional file 1). As the fruit matured, SSC increased in response to ethylene and propylene, with a maximum fold-change, between harvest and 5 days after treatment, at 175 DAFB. At the beginning of the time course (140 DAFB), the fruit did not soften when treated with ethylene or propylene. A small drop in firmness, was observed following a one-day treatment of high propylene or ethylene, for treatments at 147 DAFB. The amount of ethylene-induced softening increased as the fruit matured, with a maximum softening response first observed in samples harvested at 175 DAFB. Interestingly, fruit harvested subsequently (between 175 DAFB and 210 DAFB), displayed a reduced softening response to ethylene/propylene. The maximum softening response to ethylene was again observed for fruit harvested after 210 DAFB (Fig. 3b). Softening displayed dose dependent response, with lower concentrations of propylene showing reduced softening. As the fruit progressed through Phase 1 ripening, less propylene was required to achieve a full softening response. Finally, the propylene and ethylene treatments resulted in only a small effect on the rate of colour change within the five-day assessment period (Fig. 3c).

No endogenous ethylene was produced by fruit after propylene or ethylene treatments until 175 DAFB (black bar, Fig. 3d). A significant amount of endogenous ethylene was produced (compared to untreated fruit, $P<10^{-6}$ ) at this developmental point, five days after an ethylene or high propylene treatment. The amount of ethylene produced ( 5 days after treatment) between 182 and 210 DAFB was significantly lower $(P<0.001$ at $182 \mathrm{DAFB}, P<0.01$ at 189 DAFB, not significant at 197 DAFB, $P<0.001$ at 203 DAFB and $P<10^{-6}$ at 210) (blue bar, Fig. 3d). Higher amounts of endogenous ethylene were again produced at 217 and 224 DAFB. The reduced ethylene production observed between 182 and 210 DAFB was consistent with a reduction in softening observed in the same period (Fig. $3 \mathrm{~b}$ ). This result was also seen in batches of fruit treated with high doses of 


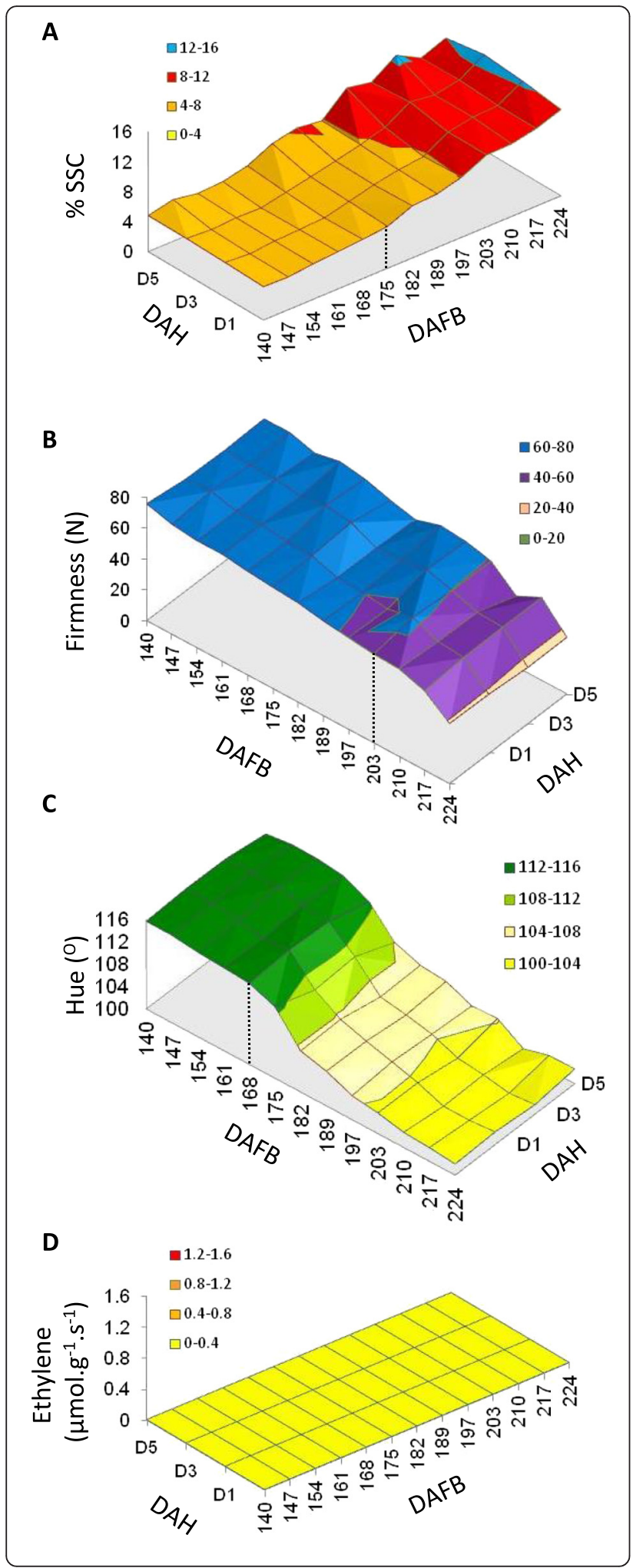

Fig. 2 Physiological changes and ethylene production in kiwifruit stored in air during late maturation and Phase 1 ripening. Fruit were harvested from 140-224 days after full bloom (DAFB; BBCH stages 79-87) and stored in air for 1, 3 or 5 days after harvest (DAH). a Soluble solids content (SSC), b. Fruit firmness, c. Flesh colour, d. Endogenous ethylene production. Dashed vertical lines show significant changes in the physiology as described in the text

propylene (Fig. 3d). This observation suggests that following maturation there is a developmental progression in Phase 1 ripening through three stages; a start when the fruit are competent to respond to ethylene in a reduced manner but do not produce ethylene (147-175 DAFB), a period where endogenous ethylene production is repressed (to 210 DAFB), and finally a late stage after which endogenous ethylene production is not repressed (217 DAFB onwards).

\section{Alignment of physiological changes with development associated genes}

Physiological changes that were observed during maturation and the three stages of Phase 1 ripening, were aligned with the expression of five previously reported ripening-associated genes [33]. RNA was extracted from fruit at 140 DAFB when no ripening-associated responses were observed (except a small increase in SSC); from fruit at 161,168 , and 175 DAFB corresponding to the development of competency to respond to ethylene, and the breakdown of stored starches and finally from fruit at 217 and 224 DAFB, with the start of on-vine softening. The treatment-time points selected were at harvest, after $24 \mathrm{~h}$ high propylene treatment ( 1 day after harvest), and 2 days later (3 days after harvest) (see schema in Fig. 1).

In the 'at-harvest' samples through the maturation period, there were only small transcriptional changes observed in two soluble sugar-related genes $(\beta-A M Y L A S E$ $(\beta-A M)$ and SUCROSE SYNTHASE (SUSA)) and the two softening-related genes (PECTIN ESTERASE (PE) and EXPANSIN (EXP)) (Fig. 4, Additional file 2). The colourrelated gene CHLOROPHYLL BINDING PROTEIN (CBP) showed a decrease in expression through Phase 1 ripening. In fruit that were not treated with propylene the effect of harvest over three days was initially minimal, but at 224 DAFB the sugar and cell wall related genes showed an increase in expression 1-3 days post harvest.

Consistent with the physiology, all genes tested except $C B P$, showed no change in expression after propylene treatment at 140 DAFB. From 161 DAFB onwards, a range of expression changes were observed in response to propylene treatment. The soluble sugar-related genes SUSA and $\beta-A M$ showed similar expression patterns with upregulation at 3 days after harvest (DAH) in 161 DAFB fruit, no response at $168 \mathrm{DAFB}$, transient up-regulation at 1 $\mathrm{DAH}$ for fruit at $175 \mathrm{DAFB}$, and a sustained up-regulation 


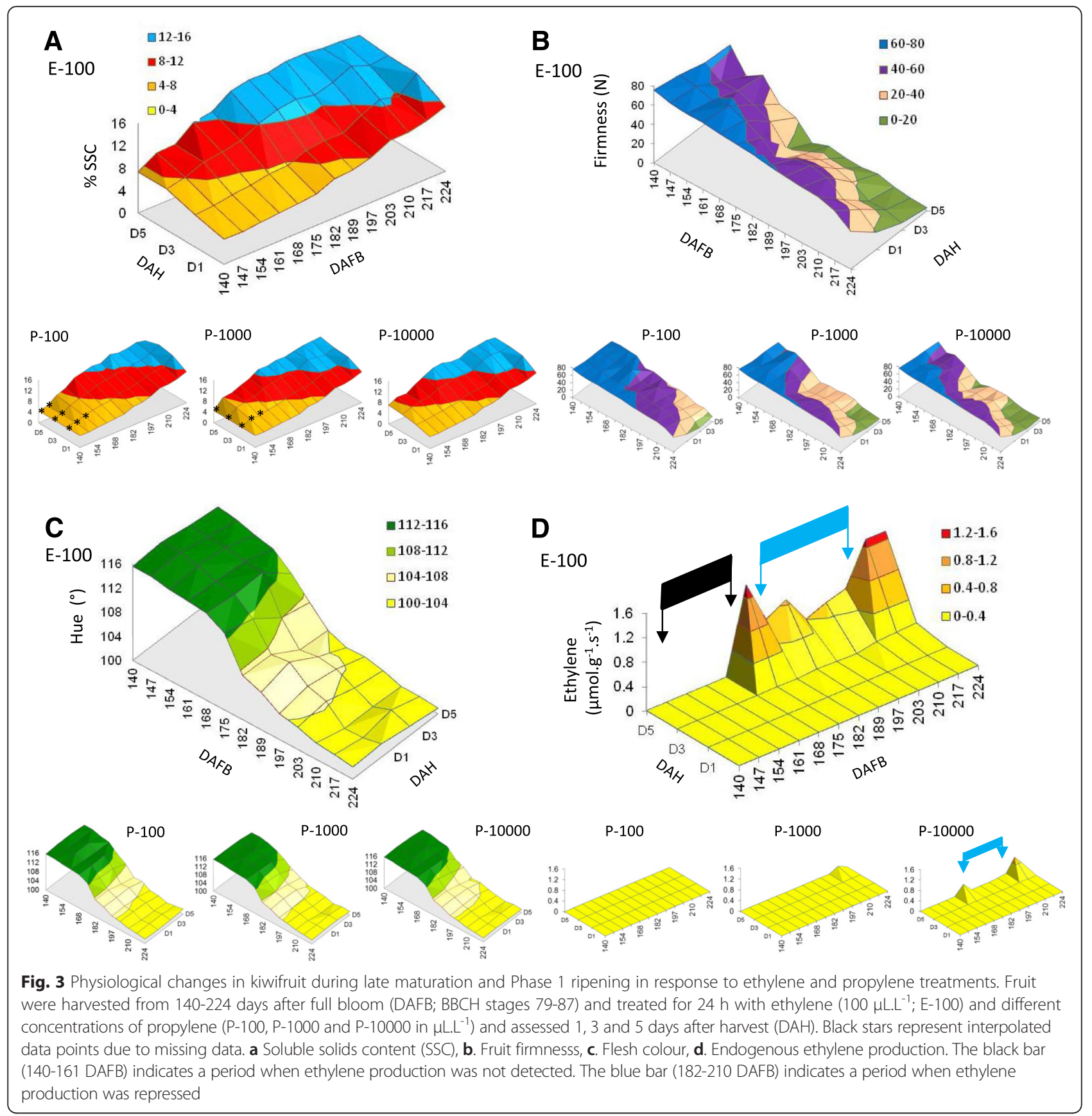

at both 1 DAH and 3 DAH in fruit from 217 DAFB onwards. With the early ripening genes $P E$ and EXP, there was no response at $140 \mathrm{DAFB}$, a transient up-regulation at $1 \mathrm{DAH}$ for fruit at $161 \mathrm{DAFB}$, no response at 168 and 175 DAFB, and a sustained up-regulation at $1 \mathrm{DAH}$ and 3 DAH from 217 DAFB onwards (Fig. 4).

\section{Identification of genes associated with ethylene biosynthesis and transduction}

As ethylene production and perception is central to the response-time dimension, we undertook a detailed study to identify all the ethylene biosynthetic and signal transduction genes in the kiwifruit genome [48]. Using lists of the auto-annotated genes we searched for descriptors associated with ethylene biosynthetic and transduction pathways (Table 1). Ten annotated SAM synthetase genes were identified, only one of which has been previously identified (Fig. 5a) [46]. Thirteen ACC SYNTHASE-like genes were selected, of which only one (ACS1) has been published $[45,46]$. In other species the ACS proteins have been divided into three classes (I-III), depending on presence of phosphorylation sites (Class I, 


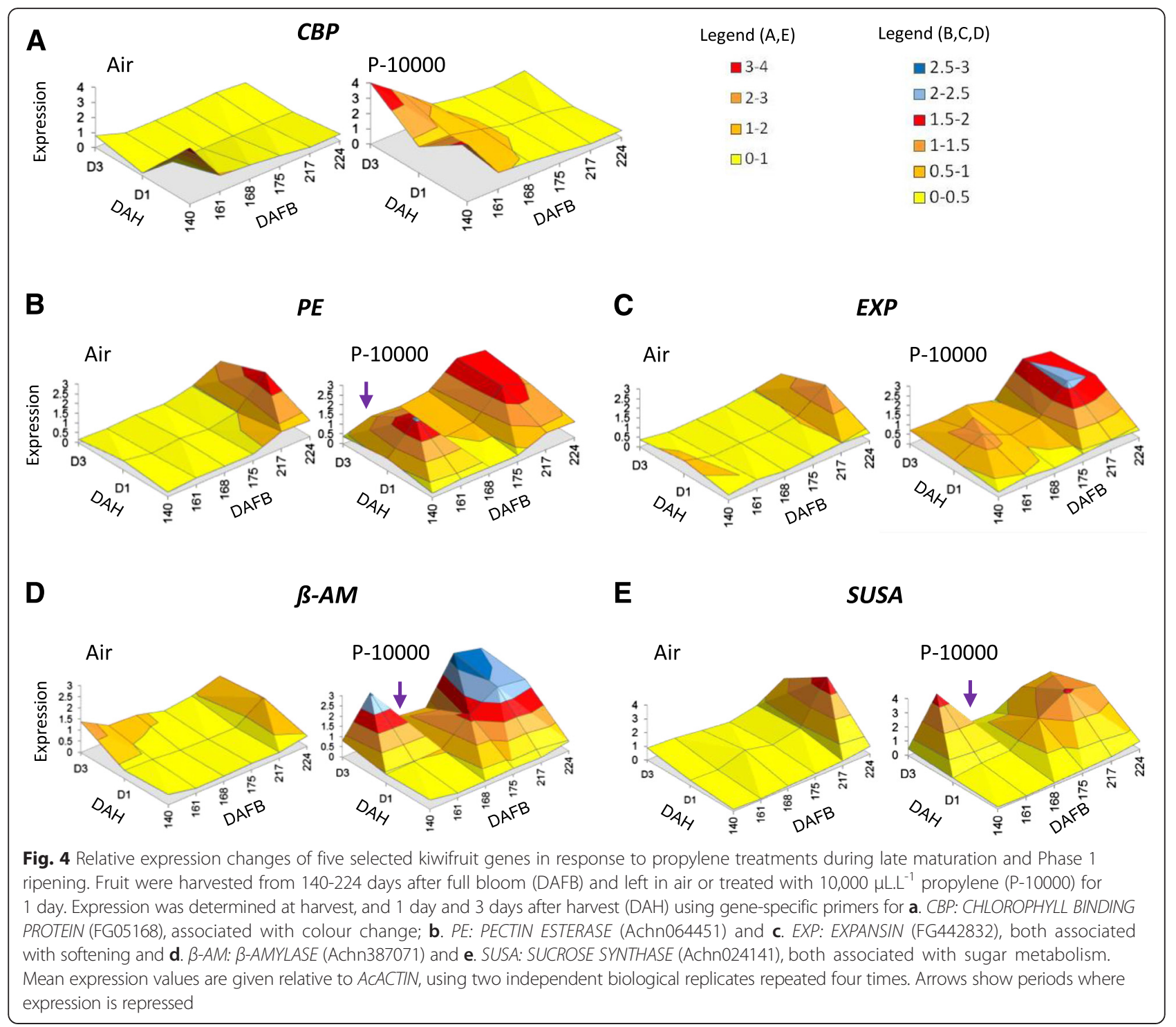

Table 1 Numbers of A.chinensis genes associated with ethylene biosynthesis and transduction annotated in the 'Hongyang' genome (for gene names see Additional file 4)

\begin{tabular}{ll}
\hline Name & Numbers of predicted genes \\
\hline SAM SYNTHASE & 10 \\
ACC SYNTHASE & 13 \\
ACC OXIDASE & 54 \\
Ethylene receptors & 9 \\
EIN3 & 7 \\
ETO & 4 \\
ERF/AP2 & 209 \\
\hline
\end{tabular}

II) and a WVF and RLSF C-terminal TOE (Target of ETO1) domain (Class II) which confers instability to the proteins. Three ACS proteins contained just the RLSF (Class I), one had both domains (Class II), and nine had neither of these domains (Class III) (Fig. 5c). ACS proteins in Class II are rapidly degraded through the action of an F-Box protein ETHYLENE OVER PRODUCER (ETO); and four ETO-like genes were identified in the kiwifruit genome. There were ninety-four ACC OXI$D A S E$ annotated genes, nine of which have been published [8]. Alignment of the protein sequences of these gene models suggested that 54 had a primary structure similar to $A C O$-like genes.

In the ethylene detection and signal transduction pathway, nine annotated ethylene receptors were identified in the annotated kiwifruit gene models, four of which have been published [45] (Fig. 5b). Further analysis 


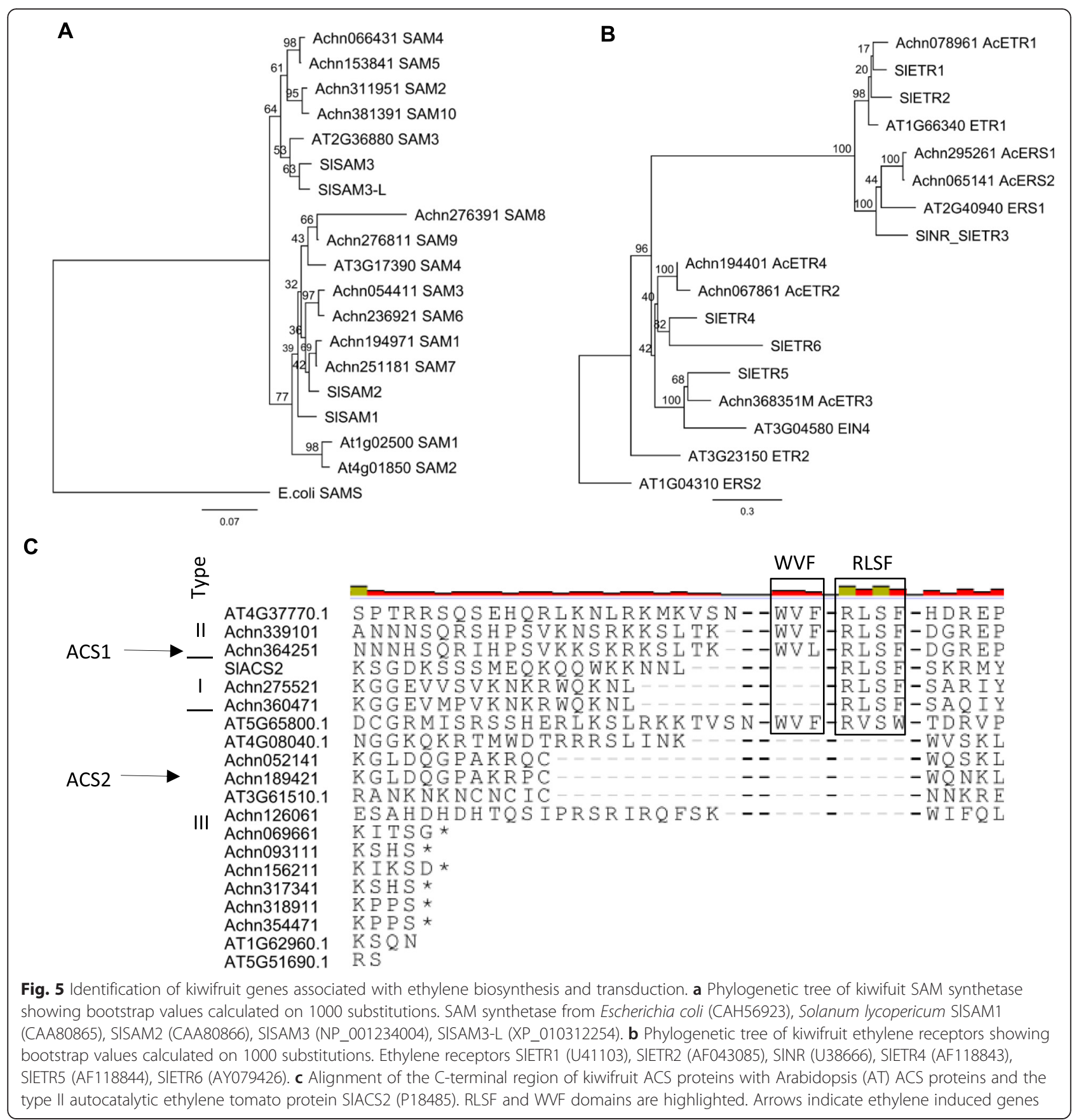

showed that two of these models did not have the all the receptor domains and one was truncated, suggesting these were not functional receptors. Ethylene receptors fall into four main classes of genes, these include the ETHYLENE RESPONSE1 (ETR1), ETHYLENE RESPONSE SENSOR1/ NEVER RIPE (ERS1/NR), ETHYLENE INSENSITIVE4 (EIN4) and ETHYLENE RESPONSE2 ETR2-like genes. Kiwifruit had representative genes in all these gene classes. The transcriptional control of the ethylene signal is through ETHYLENE INSENSITIVE3 (EIN3) and ETHYLENE RESPONSIVE FACTOR/APETALA2 (ERF/AP2) class of genes. In the annotated kiwifruit genes seven EIN3-like genes were observed, and 209 ERF/AP2-like genes, of which 182 had a conserved DNA binding domain.

Identification of ripening associated genes using a mRNAseq screen and expression analysis of selected genes Genes involved in ethylene biosynthesis, ethylene response but also transcription factors involved during fruit maturation and ripening belong to large multigene families (Table 1). To select specific ethylene associated genes to analyse further, we used an RNA-seq screen to 
identify genes within the 2 dimensional space, by selecting time points along the two boundaries. In the ethylene response time dimension, samples were harvested from fruit at 231 DAFB after exogenous treatment with $100 \mu \mathrm{L} . \mathrm{L}^{-1}$ ethylene for $24 \mathrm{~h}$, immediately following the ethylene treatment (1 DAH), 1 day (2 DAH) and 3 days (4 DAH) following treatment. Along the developmental stage dimension we chose harvest samples through Phase 1 ripening (147, 168, 175, 224 and 231 DAFB). (Figure 1, Additional file 3).

The expression of each of the ethylene biosynthetic and signal transduction associated genes identified in the kiwifruit genome was examined in this screen, and genes that appeared to be upregulated in the ethylene response time dimension at 231 DAFB were identified. Of the ten SAM synthetase genes, three had high (Reads Per Kilobase per Million) RPKM values throughout the experiment (SAM6, SAM7 and SAM10), and two appeared to be upregulated with ethylene (SAM1 and $S A M 2$ ) (Additional file 4). Of the thirteen $A C S$ genes, two were strongly upregulated with ethylene (ACS1,belonging to Class I), and ACS2 belonging to Class III). Of the $54 A C O$ genes, three were strongly upregulated by ethylene (ACO1, ACO2/3 and ACO5). The ERS1 and ETR2 classes of ethylene receptors also showed upregulation in expression (Additional file 4).

The expression patterns of four ethylene-related genes with the biggest changes in RPKM values in the responsetime dimension in each gene family (SAM1, ACS1, ACO2/ 3 and ETR2) were assessed by qPCR at harvest and at time points previously described (Fig. 6, Additional file 5). In fruit at harvest during Phase 1 ripening, SAM1, ACS1 and $A C O 2 / 3$ did not increase in expression, while ETR2 showed an increase during Phase 1 ripening. There was no increase in $A C S 1$ expression in air treated fruit over the 3 day period, but $A C O 2 / 3$ and ETR2 both showed an increase as the fruit went into the late Phase 1 ripening stage (224 DAFB).

In propylene treated fruit, $S A M 1$ showed a sustained increase in expression at $140 \mathrm{DAFB}$, and as the fruit underwent Phase1 ripening (168 - 224 DAFB $)$ a transient increase in expression was observed. ACS1 showed no response at 140 DAFB and 161 DAFB and a transient increase in expression at 168 and 175 DAFB. There was a minor response at 217 DAFB and then a partial sustained response at $224 \mathrm{DAFB}$. The $A C O 2 / 3$ and ETR2 genes had more complex responses, with $A C O 2 / 3$ showing low transient response at $140 \mathrm{DAFB}$, a low sustained response at 161 DAFB and 168 DAFB, a transient response at 175 DAFB and a high sustained response at 217 DAFB onwards. ETR2 had no response at 140 DAFB to ethylene and then low sustained response at 161 DAFB, no response at 168 DAFB, a transient response at $175 \mathrm{DAFB}$, and an increasing sustained response at 217 and 224 DAFB.

\section{Regulators associated with competence to ripen}

The MADS-box class of genes have been shown to be key regulators of ripening in other fruit species. These include the tomato genes SIRIN (SEPALLATA-like), SITDR4 (FUL-like) and SITAGL1 (AGAMOUS-like). The complex intron/exon structure and alternative splicing of the MADS-box genes makes the automated annotation of this class of genes difficult. The automated prediction of MADS-box genes in the kiwifruit genome is therefore not accurate. Indeed, of the three kiwifruit SEPALLATA genes published [33, 49], only the SEP1 and $S E P 2$ are annotated in the 'Hongyang' genome sequence. Notably, SEP4 (GB - HQ113364) was absent from the gene models, as was FUL1 (GB - HQ113357). There were, a further two gene models that showed high similarity to the SIRIN DNA binding domain. When examined in more detail, these AcSEP-like genes showed lower homology to SIRIN across the whole protein sequence, with the SEP4 gene displaying the highest homology (64\% identity) throughout the entire gene (Additional file 6). A scan of the mRNA-seq expression data for all genes with a computer assigned MADS-box function, identified a fourth MADS-box gene (Achn135681) with a large change in expression during maturation. This gene was closest to the APETALA3 (AP3) class of MADS-box genes.

The expression of the closest kiwifruit RIN/FUL/ TAGL1- and AP3- like MADS-box genes over Phase1 ripening, with and without propylene showed that the MADS-box gene SEP4/RIN showed a decrease in expression as the fruit progressed through Phase 1 ripening, and early in Phase 1 ripening (147-168 DAFB) showed little response to the propylene treatment. However after 175 DAFB there was a transient 4-fold upregulation in expression with the propylene treatment. This transient increase continued to $3 \mathrm{DAH}$ as the fruit went into rapid softening (224 DAFB) (Fig. 7a, e). FULlike increased four-fold as the fruit matured (Fig. 7b/e). When the fruit were treated with propylene there was no difference in this induction, showing this gene acts independently of ethylene. At early Phase 1 ripening (161-168 DAFB) the TAGL1 gene showed a two-fold increase in expression with an propylene treatment and following harvest. However this increase was not observed later in Phase 1 ripening (Fig. c, Additional file 7). The AP3-like gene was highly expressed at 140 DAFB and had a 4-fold decrease in expression as the fruit entered Phase 1 ripening. When treated with propylene this gene was rapidly downregulated (Fig. 7d, Additional file 7).

\section{Transcriptional control of the SEP4/RIN like gene}

A $3.2 \mathrm{~kb}$ region upstream of the transcriptional start, was firstly scanned for potential RIN-like CaRG sequences. In tomato the preference RIN binding site is $\mathrm{CCA}(\mathrm{A} / \mathrm{T})(\mathrm{A} / \mathrm{t})(\mathrm{A} / \mathrm{T}) \mathrm{ATAG}$, but RIN can also bind to a 


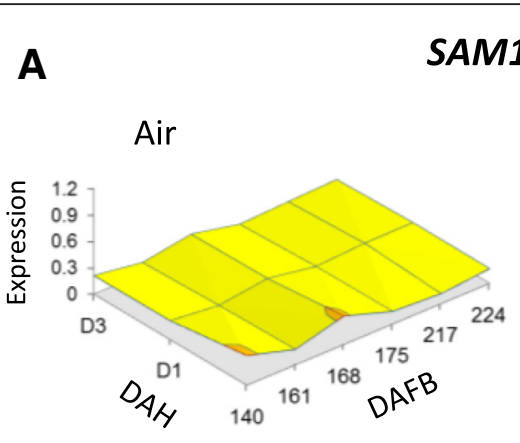

B

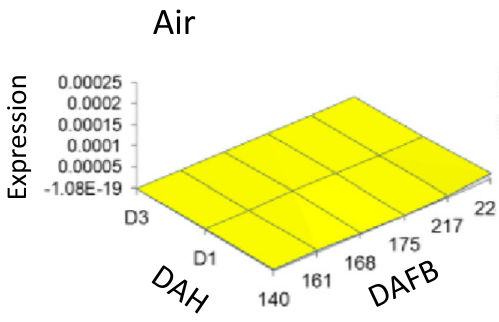

ACS1

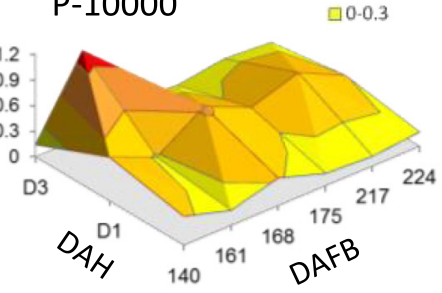

$\square 0.0002-0.00025$

= $0.00015-0.0002$ $\square 0.0001-0.00015$ $\square$ 5E-05-0.0001 $\square 0-5 \mathrm{E}-05$
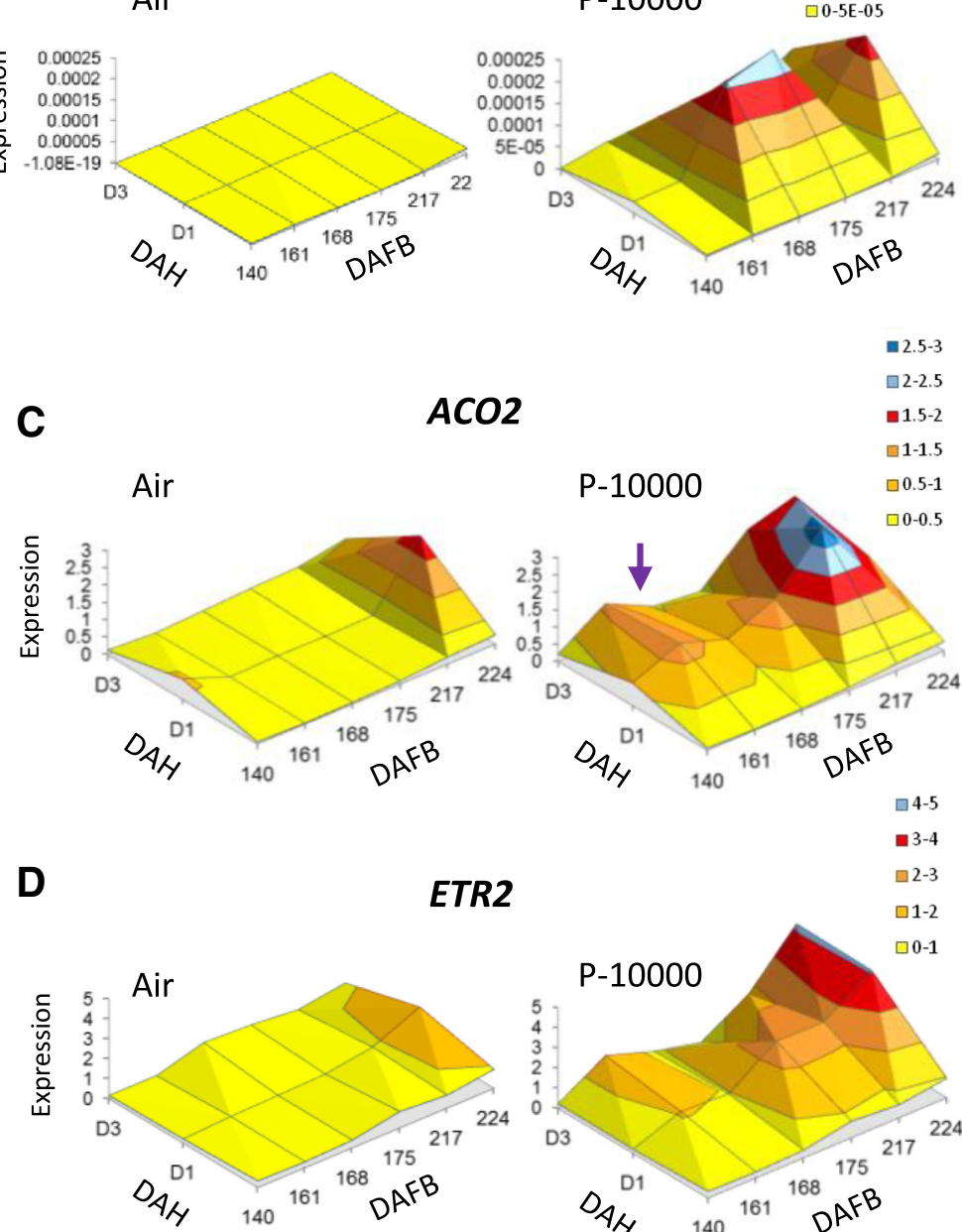

=2.5-3

$\square 2-2.5$

a1.5-2

$\square$ 1-1.5

$\square 0.5-1$

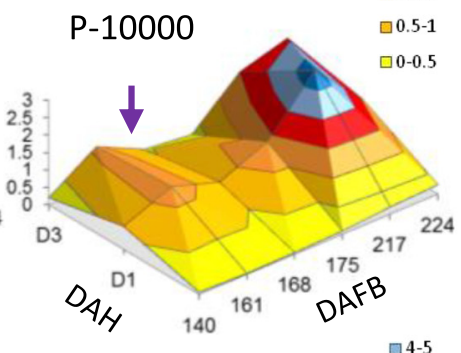

$\square 4-5$

$\square 3-4$

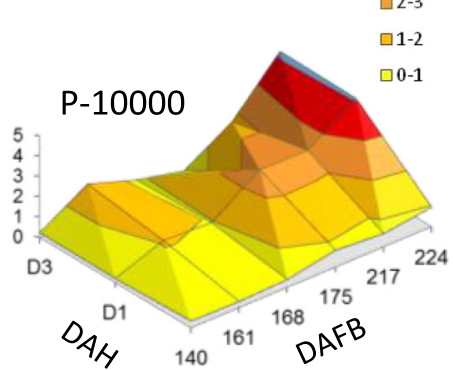

Fig. 6 Expression of selected kiwifruit genes associated with ethylene biosynthesis and perception. Fruit were harvested from 140-224 days after full bloom (DAFB; BBCH stages 79-87) and treated in air or with 10,000 $\mu \mathrm{L} . \mathrm{L}^{-1}$ propylene (P-1000) for 1 day. Expression was determined at harvest, and 1 day and 3 days after harvest (DAH) using gene-specific primers for: a. ACSAM1: S-ADENOSYL METHIONINE SYNTHETASE1 (AChn194971), b. ACACS1: ACC SYNTHASE1 (Achn364251), c, AcACO2: ACC OXIDASE2 (Achn326461), and d, AcETR2: ETHYLENE RECEPTOR2 (Achn067861). Mean expression values are given relative to $A C T I N$, using two independent biological replicates repeated four times

more general $\mathrm{C}(\mathrm{C} / \mathrm{T})(\mathrm{A} / \mathrm{T}) 6(\mathrm{~A} / \mathrm{G}) \mathrm{G}$ CaRG box [50]. In the kiwifruit genome sequence there were two CaRG sequences within the first $2 \mathrm{~kb}$ of the SEP4/RIN promoter. Also within this promoter is a potential EIN3 binding site $(\mathrm{A}(\mathrm{T} / \mathrm{C}) \mathrm{G}(\mathrm{A} / \mathrm{T}) \mathrm{A}(\mathrm{C} / \mathrm{T}) \mathrm{CT})$, as well as a PS1 sequence that EIN3 has been shown to bind to [51] (Fig. 8a). To test whether these sites are functional, the $3.2 \mathrm{~kb}$ fragment was inserted into a Luciferase reporter 


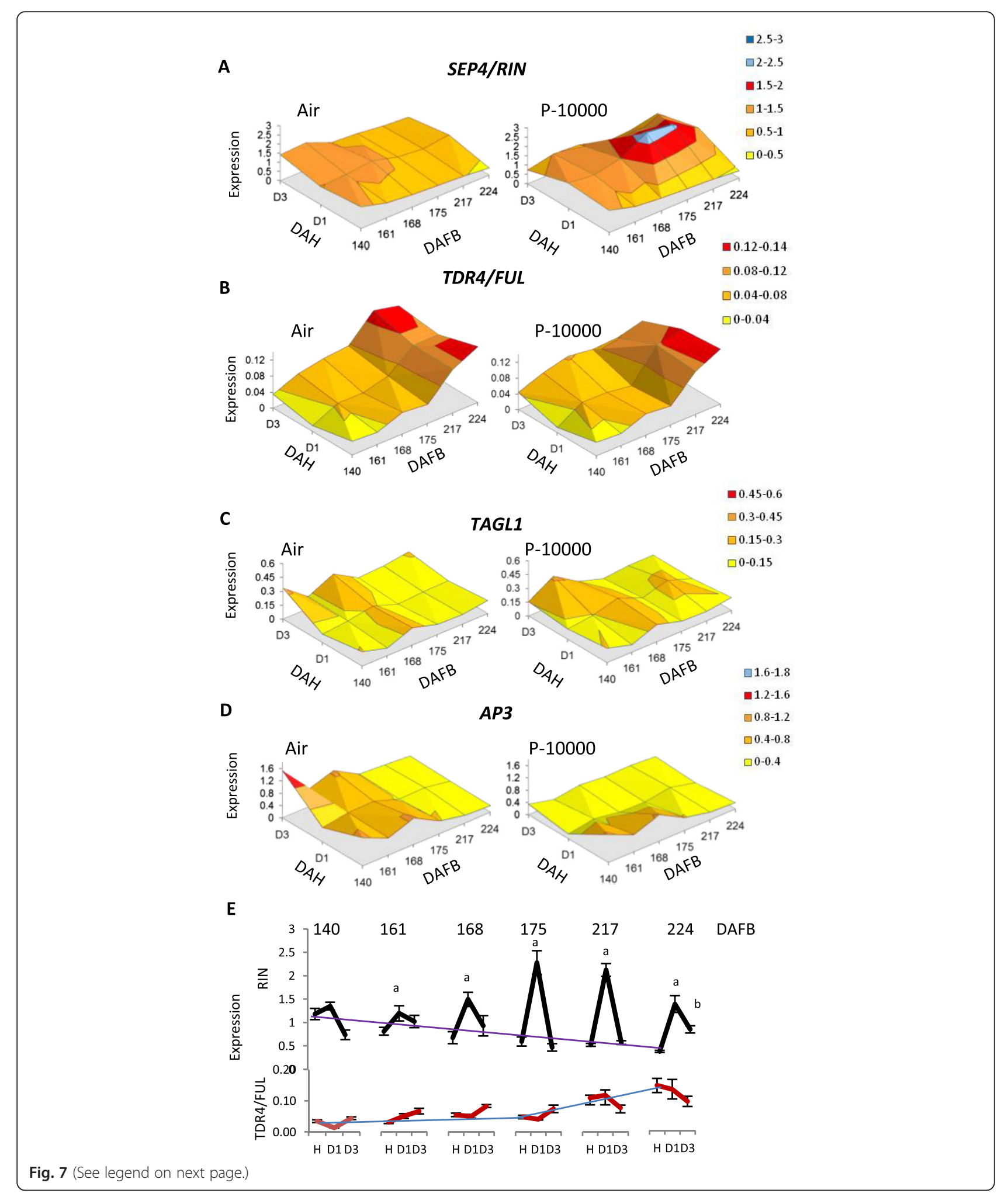


(See figure on previous page.)

Fig. 7 Relative expression changes of MADS box genes in response to propylene treatments during late maturation and Phase 1 ripening. Fruit were harvested from 140-224 days after full bloom (DAFB; BBCH stages 79-87) and treated in air or with 10,000 $\mu$ L.L ${ }^{-1}$ propylene (P-1000) for 1 day. Expression was determined at harvest, and 1 day and 3 days after harvest (DAH) using gene-specific primers for: a. SEP4/RIN (HQ113364), $\mathbf{b}$. TDR4/FUL (HQ113357), c. TAGL1 (Achn121201), d. AP3 (Achn135681). Mean expression values are given relative to ACTIN, using two independent biological replicates repeated four times. e A comparison of SEP4/RIN response to P-10000 treatment and TDR4/FUL. SEP4/RIN showed a decrease in expression through maturity (purple line) and a transient upregulation with propylene. TDR4/FUL has little increase in expression until 175 DAFB, then increases (blue line). It has no significant response to propylene. Significance response to propylene compared to harvest time point $(\mathrm{a}, \mathrm{b}=p<0.01)$

construct [52] and transiently co-injected into Nicotiana benthamiana leaves with the kiwifruit SEP4/RIN gene driven by a $35 \mathrm{~S}$ promoter. It was found that SEP4/RIN was unable to transactivate the RIN promoter. When the $3.2 \mathrm{~kb}$ promoter fragment was co-infiltrated with three kiwifruit EIN3 transcription factors driven by a $35 \mathrm{~S}$ promoter, it was shown that the ethylene associated EIN3-like genes could transactivate the promoter (Fig. 8b).

\section{The SEP4 RIN-like gene induces ethylene production in fruit}

In other species, there has been a strong association between the MADS-box gene RIN and ethylene biosynthesis. For example, the SIRIN gene binds and activates itself and SlACS2 [50]. Because of the close similarity

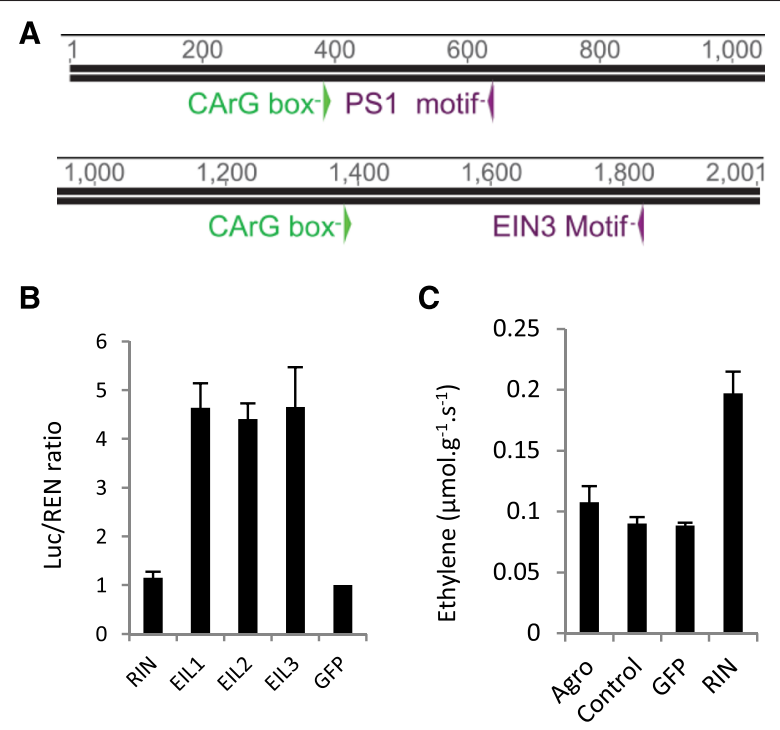

Fig. 8 a The $2 \mathrm{~kb}$ region upstream of the transcriptional start of the SEP4/RIN gene showing potential EIN3 binding sites (including a putative PS1 binding site) and MADS box binding CaRG box consensus sequences. b Transient transactivation of a $3.2 \mathrm{~kb}$ RIN promoter fragment by RIN and EIN3-like transcription factors in tobacco (N. benthamiana) leaves with SEP4/RINgene (RIN) and three EIN3 like genes (EIL) compared to a 35S:GFP control (GFP). c Averages of Ethylene emission from three independent experiments of $A$. eriantha fruit transiently expressing a 35S:SEP4 (RIN) gene compared to untransformed Agrobacterium tumefaciens (Agro), water (control) and Agrobacterium containing a 35S:GFP gene (GFP) with SIRIN, and expression pattern, the construct containing the SEP4/RIN gene driven by a $35 \mathrm{~S}$ promoter was tested transiently in mature A. eriantha fruit [53]. A.erinantha fruit were chosen as they are amenable to transient expression, and produce very low amounts of ethylene at ripening [54]. Transiently injecting Agrobacterium containing the 35S:AcSEP4/RIN construct into mature fruit produced a consistent increase in endogenous ethylene compared with three controls, water injection, Agrobacterium alone and Agrobacterium containing a 35S:GFP (Green Fluorescent Protein) gene construct (Fig. 8c).

\section{Discussion}

During development in all fruits, there is a period when the fruit becomes competent to ripen. This is a major change in the fruit's properties, as it alters the fruit to be more attractive to seed-dispersing organisms, and usually coincides with seed maturation. The switch is often facilitated by large changes in phytohormone production, especially ethylene. In model fruit species such as tomato and grape there is growing molecular understanding of how some of the key switches regulate this transition. In tomato, ripening is predominantly regulated by ethylene, whilst in grape ripening ethylene has a relatively minor role. At the molecular level the best studied regulator is the RIN MADS-box gene, which acts in a heterotetrameric complex with FUL/TDR4 FUL2 and/or TAGL1 to bind and activate many genes associated with fruit ripening [21, 26, 28, 29, 50]. RIN is highly and constantly up-regulated during fruit ripening in tomato [17], banana [55], strawberry [18], and apple [19], and in tomato the FUL/TDR4 RIN complex has been shown to bind and activate the promoter of the ethylene biosynthesis genes $A C S 2,4$ and RIN itself [26, 28, 29]. In this study we have shown that a RIN-like gene (previously published as AcSEP4 [33, 49] is associated with autocatalytic ethylene-associated ripening. Unlike tomato RIN [56], but consistent with grape VviSEP4 (GSVIVG0101051001) [57], following maturation (or veraison) the expression of this kiwifruit $R I N$-like gene decreases (Fig. 7b). This suggests that in grape and kiwifruit RIN cannot auto-activate itself, and even suggests the presence of an additional repression during this time. Ethylene (or propylene) is able to induce RIN 
expression in tomato and kiwifruit, however in kiwifruit, subsequent removal of ethylene causes this gene to be downregulated again (Fig. 7b), further supporting a repression mechanism. Transient experiments performed in tobacco indicate that the kiwifruit RIN does not activate RIN and there is no increase in RIN expression when the AcFUL is developmentally turned on, or when RIN expression is induced with ethylene, suggesting a mechanism by which the hybrid ripening is controlled (Fig. 9).

While the controllers of kiwifruit Phase-1 ripening (non-autocatalytic ethylene associated) are yet to be fully identified, a key candidate is the FUL/TDR4-like gene (Achn247791), which in tomato has been shown to be a major controller of many ripening factors [21, 28]. In kiwifruit the increase in FUL coincides with the start of rapid softening (Figs. 2 and 7) suggesting a mechanism by which cell wall related genes such as PE and EXP (Fig. 4) are upregulated. This would be consistent with tomato, where authors have postulated that SIFUL/TDR4 controls an ethylene independent ripening process [21], and our results in kiwifruit would support the suggestion that this occurs independently of RIN. In the presence of ethylene (or propylene), these cell wall genes are upregulated, which could be due to the presence of RIN or other ethylene-related cis-elements in their promoters. The switch between a transient activation of these genes and sustained activation late in maturity may be explained by the developmentally controlled upregulation of FUL. The third kiwifruit gene of the MADS-box complex, TAGL1 does not appear to change during development during Phase-1 ripening. TAGL1 is partially upregulated with ethylene similar to tomato [22], but not in a sustained manner (Fig. 7).

In this study a third floral identity-like gene (AP3), showed a large decrease in expression as the fruit transitioned into ripening competence. An AP3 tomato homologue TDR6 is also expressed early in fruit maturation, is down-regulated at ripening, and interestingly showed a possible interaction with TDR4 (FUL) in a yeast 2-hybrid experiment [58]. Consistent with that of Arabidopsis AP3, the expression appears to be auto-inhibitory [23], with a decrease in expression in ripening fruit, and it is inhibited by ethylene. Whether this gene plays a role in the regulation of ripening is yet to be seen.

As the fruit mature there is an increase in sensitivity to ethylene, with the lower concentrations of propylene inducing a more significant response over time (Fig. 1). Each of the ripening responses shows different sensitivities to ethylene and propylene, with sugars showing an early high sensitivity and fruit firmness showing a lower sensitivity. This implies there is a similar sensitivity dependency mechanism occurring in kiwifruit as proposed in apple $[59,60]$. Interestingly, kiwifruit colour change shows little effect from the treatment with ethylene, suggesting that de-greening is probably associated with developmental control rather than ethylene. At the transcriptional level, ethylene (propylene) causes a reduction in CBP transcription, showing that some colour-related mechanisms are transcriptionally modulated by ethylene. The lack of phenotypic changes may be however partially due to the short 5-day assessment period used in this study.

\section{Conclusions}

With the development of more sensitive detectors, and the use of molecular tools outside the classic model organisms, the distinctions between autocatalytic ethylene associated (climacteric) and non ethylene associated (non climacteric) fruit ripening has eroded [61]. Here we propose a model (Fig. 9) in which, through changes in the regulation of ethylene regulating RIN-like genes and ethylene independent FUL/TDR4 like genes, the differences between fruit ripening between these two classes are not so dissimilar.
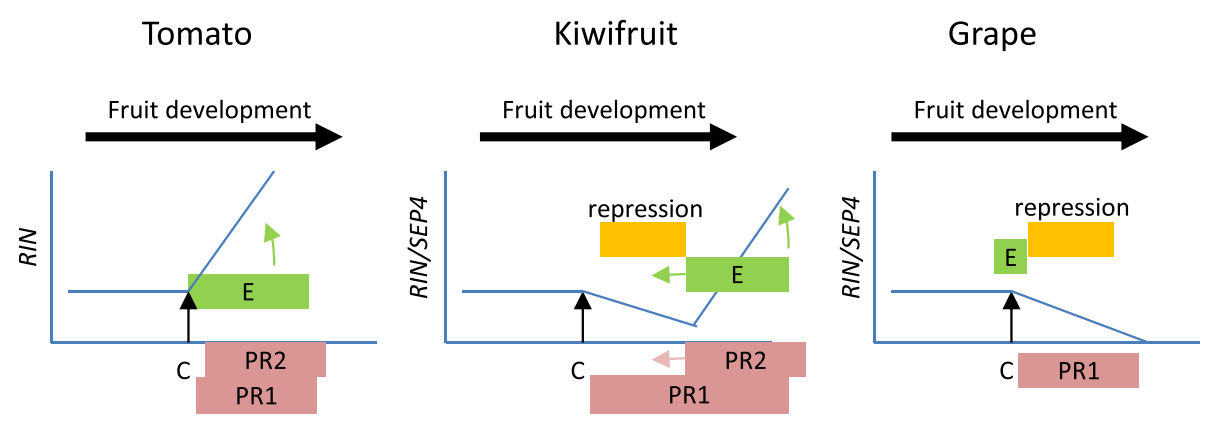

Fig. 9 A simplified model of the role of RIN-like genes during fruit maturation and ripening in different scpecies. RIN expression (blue line) correlates with ethylene production (E). Once the fruit is competent to ripen (C) RIN can induce ethylene dependent ripening (Phase 2 ripening PR2), but in the absence of ethylene (and RIN), ethylene independent ripening progresses (Phase 1 ripening PR1). In tomato RIN activates both ethylene and itself (Alba et al. 2005, Fujisawa et al. 2013) $[29,56]$ progressing PR1 and PR2 ripening simultaneously, while in kiwifruit and grape there is a down regulation of RIN expression following competence to ripen (and in grape veraison) (Pilati et al. 2007) [57] allowing PR1 ripening to occur independently. In kiwifruit this repression can be reversed later in maturity, or with the application of ethylene. Kiwifruit thus shows a hybrid ethylene independent-dependent mechanism with phase 2 ripening being likely to be controlled by SEP4/RIN 


\section{Methods}

\section{Kiwifruit sampling}

Yellow-fleshed kiwifruit (Actinidia chinensis (Planch.) var. chinensis 'Hort16A') fruit were sampled from The New Zealand Institute for Plant \& Food Research Limited research orchard at Te Puke, Bay of Plenty, New Zealand, during the 2011 harvest season. Sampled fruit were, unless otherwise specified, held in ethylene-free rooms under controlled conditions at temperatures between $18{ }^{\circ} \mathrm{C}$ and $20^{\circ} \mathrm{C}$.

\section{Fruit harvest and assessment}

Two batches of 60 fruit each from A. chinensis 'Hort16A' were harvested at weekly intervals over a 14-week period covering maturation and ripening. Each batch of fruit was independently processed for biological replication and separated into at-harvest samples and five treatments: air, $100,1000,10,000 \mu \mathrm{L} . \mathrm{L}^{-1}$ propylene, or $100 \mu \mathrm{L} . \mathrm{L}^{-1}$ ethylene, for $24 \mathrm{~h}$ in $20 \mathrm{~L}$ sealed containers. Propylene was selected as a viable alternative to ethylene as a treatment for the activation of the ethylene response for two reasons, 1) in order to validate that ethylene detected after treatment was a result of endogenous ethylene production and not confounding from residual treatment gas and, 2) to increase the treatment volume to a amount that could be accurately measured and handled. Air was circulated continuously and lime was used to absorb $\mathrm{CO}_{2}$. The fruit were removed and immediately assessed (Day 1 (Day after Harvest - DAH), or were stored for 2 (Day 3) or 4 days (Day 5) in an ethylene-free room at $20{ }^{\circ} \mathrm{C}$ and then assessed. Physiological assessments of ten randomly selected fruit from each biological replicate at each time of harvest were assessed. Each fruit was weighed and placed in a 500-mL airtight pot for $45 \mathrm{~min}$, from which ethylene concentrations of $1 \mathrm{~mL}$ air headspace were assessed using a Philips PU4500 ${ }^{\circ}$ Gas Chromatograph machine. Destructive fruit assessment was conducted rapidly to reduce wound-associated transcriptional changes. Fruit firmness was determined using a Fruit Texture Analyser (GUSS ${ }^{\text {тм }}$ Fruit texture analyser GS-14 ${ }^{\circ}$, South Africa) with a 7.9$\mathrm{mm}$ probe at $20 \mathrm{~mm} . \mathrm{s}^{-1}$ following removal of a $1 \mathrm{~mm}$ thick slice of skin and outer pericarp at two locations perpendicular to each other at the fruit equator. Flesh colour was determined in an LCH colour space using a CR 300 ChromaMeter (Konica Minolta ${ }^{\mathrm{TM}}$ CR- $300^{\circ}$ Minolta, Japan) with a C65 light source at two locations perpendicular to each other at the fruit equator at a depth of about $2 \mathrm{~mm}$. Fruit were cut in half and the percentage of fully coloured black seeds was recorded. Soluble solids contents were determined from juice taken from both ends of the fruit using a refractometer (ATAGO ${ }^{\circ}$ ATC-20E, Japan).

\section{Extraction of RNA for gene expression analysis}

Four fruit were selected that displayed the closest firmness to the mean for tissue sampling for expression analysis. Sampled fruit tissue was cut into small pieces, rapidly frozen in liquid nitrogen, and stored at $-80{ }^{\circ} \mathrm{C}$ prior to further molecular analysis. RNA-seq analysis was performed on selected samples at maturity and also on an additional set of fruit harvested 231 DAFB (softened on vine). This second set of fruit were chosen as they would be fully responsive to ethylene. Fruit were harvested, treated with $100{\mathrm{uL} . \mathrm{L}^{-1}}^{-}$ethylene, and assessed as above 1 day, 2 days and 4 days following treatment (Additional file 4).

Total RNA was extracted from $\sim 2 \mathrm{~g}$ of $A$. chinensis 'Hort16A' fruit material as described in [62]. Contaminating genomic DNA was removed from $10 \mu \mathrm{g}$ of each total RNA sample using an Ambion Turbo DNAse kit according to the manufacturer's specifications (http:// www.lifetechnologies.com). RNA was quantified and quality-assessed using an Agilent 2100 bioanalyzer with a RNA 6000 nanochip. RNA samples with a RNA integrity (Rin) score of $>8.0$ were used for sequencing. Messenger RNA (mRNA) sequence data were obtained using either NZGL (www.nzgenomics.co.nz) or Macrogen sequencing facility (www.macrogen.com) on an Illumina HiSeq2000 next generation sequencer, with samples barcoded 12 to a lane, with a sequencing depth of 17-27 million reads (Additional file 4).

For quantitative PCR (qPCR), RNA used for mRNAseq and a second independent biological replicate were assessed. cDNA was synthesised using an Invitrogen ${ }^{\mathrm{TM}}$ VILO kit according to the manufacturer's instructions (http://www.lifetechnologies.com). Oligonucleotide primers specific to each gene were designed using Vector $\mathrm{NTI}^{\mathrm{mm}}$ version 11.0 (Invitrogen $^{\mathrm{Tm}}$ ) using EST sequences [42]. Primer sequences are found in Additional file 8. For qPCR, four technical repeats of each sample were measure using a 384well plate LightCycler480 ${ }^{\mathrm{Tm}}$ (Roche $^{\mathrm{Tm}}$ ) and a SYBRgreen 480 LightCycler $^{\oplus}$ kit $\left(\right.$ Roche $\left.^{\mathrm{Tn}}\right)$. The identity of each amplified fragment was confirmed by sequencing. Differences in gene expression were calculated using two independent reference genes, ACTIN and EF1 $\alpha$ [63], both of which gave similar results, therefore the results presented here are relative to ACTIN. Selecting fruit close to the median firmness gave consistent results except for a single time point (168 DAFB fruit treated with 10,000 propylene, assessed after 1 day). Results from this time point were strikingly different and subsequent reassessment suggested one fruit in this batch of four was physiologically an outlier (more advanced for other ripening attributes), so data presented from this time point are from a single biological replicate.

\section{Bioinformatic processing of mRNA seq data}

mRNA-seq data were processed by first removing poor sequence quality from each read using FASTQC version 1.6.0_17. Next, each sequence read was aligned to the Actinidia gene models predicted from the kiwifruit genome 
(http://bioinfo.bti.cornell.edu/kiwi) using Bowtie2 (version 1.0.0) using default settings. Data were transferred to Bioconductor in $\mathrm{R}$ and reads were normalised to Reads per $\mathrm{Kb}$ per Million (RPKM), using the total number of aligned reads and length of the predicted genes.

\section{Phylogenetic analysis}

Alignments of conserved domains within the proteins were generated using the Geneious Pro ${ }^{\mathrm{Tw}} 7$ (www.geneious.com). Multiple alignments were performed using Genious global alignment with free end gaps method. The cost matrix was Blowsum62 and opening penalty of 30 and an extension penalty of 0 . The phylogenetic trees were built Geneious Pro $^{\mathrm{Tm}} 7$ using PHYML neighbour joining with 1000 bootstraps.

\section{Promoter analysis}

Using genomic sequence from the predicted A.chinensis genome, the promoter of the SEP4/RIN gene was amplified using two sets of primers. This approach was taken to create a ATG fusion with the Nco1 site at the start of the luciferase gene in the pGREEN vector. Primer set 1 (F) 5'Phos GATCCTAAGGTACGCACGATTGAAC and (R) 5'GCTCTCTCTCTCTCTCTCTCTACTGGTA, and primer set 2 (F) 5'CTAAGGTACGCACGATTGAACGTG and (R) 5'Phos CATGGCTCTCTCTCTCTCTCTCTC TACTG. The two $3.2 \mathrm{~kb}$ PCR products were melted and reannealed to create $\mathrm{Bam} \mathrm{H} 1$ and $\mathrm{Nco} 1$ compatible overhangs. This was annealed into the pGreenII 0800-5 LUC vector as described in [52]. Transient activation of the promoter was achieved using a 35S:SEP4/RIN construct [49], made by placing the AcSEP4 gene in front of the $35 \mathrm{~S}$ promoter using Gateway cloning (Life Technologies Ltd) and 35S:EIN3 trancription factors described by [47], and tested as described in [52].

\section{Transient assays}

Liquid Agrobacterium (strain GV101) cultures containing the 35S:SEP4/RIN construct were grown to an OD between 0.75 and 0.85 and activated in $\mathrm{Mg}_{2} \mathrm{SO}_{4}(10 \mathrm{mM})$ with acetosyringone $(1 \mu \mathrm{M})$ for $30 \mathrm{~min}$. This solution was injected into A. eriantha fruit [53] and left for 3 days before assessing for ethylene using the headspace analysis method as described above.

\section{Statistical analysis}

Analysis of physiological data presented in Additional file 1 was calculated by Post-hoc analysis of ANOVA using Tukey's honest significance test at comparable time points. Statistical calculations for significance of qPCR presented in Additional files 2 and 5 was calculated in a pairwise manner using two tailed Welch's ttests. All other statistical calculations were calculated in a pairwise manner using two tailed Student's t-tests.

\section{Additional files}

\begin{abstract}
Additional file 1: Details of physiological changes of sugar accumulation, firmness loss and ethylene biosynthesis in Actinidia chinensis 'Hort16A' kiwifruit. (PPTX 1802 kb)

Additional file 2: Relative expression changes of ripening associated genes in kiwifruit in response to propylene treatments. (PPTX 98 kb)
\end{abstract}

Additional file 3: List of ethylene-related gene expression values mined from $A$. chinensis mRNA-Seq libraries. (PPTX $36 \mathrm{~kb}$ )

Additional file 4: Physiology of selected time points for mRNA-Seq, and depth of libraries. (XLSX $1091 \mathrm{~kb}$ )

Additional file 5: Expression of selected genes associated with ethylene biosynthesis and perception. (PPTX $103 \mathrm{~kb}$ )

Additional file 6: Assesment of RIN-like genes in Actinidia chinensis 'Hort16A' kiwifruit. (PPTX 288 kb)

Additional file 7: Expression of selected MADS-box genes (RIN, TDR4, TAGL1 and AP3). (PPTX $136 \mathrm{~kb}$ )

Additional file 8: Sequences of primers used for qPCR. (PPTX $30 \mathrm{~kb}$ )

Abbreviations

$\mathrm{BBCH}$ : Biologische Bundesanstalt, Bundessortenamt und $\mathrm{CHemische} \mathrm{Industrie;}$ DAFB: Days after full bloom; DAH: Days after harvest; qPCR: Quantitative polymerase chain reaction; RPKM: Reads per Kilobase per Million.

\section{Competing interests}

The authors declare that they have no competing interests.

\section{Authors' contributions}

Data acquisition, analysis and interpretation was conducted by PAM, ACR, NJN, KG, LH, XC, PhD student PAM was supervised by JNB, KMD, and RJS. Paper writing and critical editing was undertaken by PAM, RJS, KMD, JNB and RGA. All authors have read and approved the final version of the manuscript.

\section{Acknowledgements}

This work was funded by the New Zealand Foundation for Research Science and Technology (PQA:Growing the Future Contract No. C06X0706) and Plant and Food Research CORE funding, supplied by the New Zealand Ministry for Business Innovation and Employment.

\section{Author details}

${ }^{1}$ The New Zealand Institute for Plant \& Food Research Limited (PFR), Mt Albert Research Centre, Auckland, New Zealand. ${ }^{2}$ School of Biological Sciences, University of Auckland, Auckland, New Zealand. ${ }^{3}$ PFR, Kerikeri Research Station, Kerikeri, New Zealand.

Received: 3 September 2015 Accepted: 21 December 2015 Published online: 29 December 2015

\section{References}

1. McAtee P, Karim S, Schaffer RJ, David K. A dynamic interplay between phytohormones is required for fruit development, maturation and ripening. Front Plant Sci. 2013:4:79.

2. Wang KL-C, Li H, Ecker JR. Ethylene biosynthesis and signaling networks. Plant Cell. 2002;14 suppl 1:S131-51.

3. Yoshida H, Wang KL-C, Chang C-M, Mori K, Uchida E, Ecker JR. The ACC synthase TOE sequence is required for interaction with ETO1 family proteins and destabilization of target proteins. Plant Mol Biol. 2006;62(3):427-37.

4. Wang KL-C, Yoshida H, Lurin C, Ecker JR. Regulation of ethylene gas biosynthesis by the Arabidopsis ETO1 protein. Nature. 2004;428(6986):945-50.

5. Oeller P, Lu M, Taylor L, Pike D, Theologis A. Reversible inhibition of tomato fruit senescence by antisense RNA. Science. 1991;254(5030):437-9.

6. Schaffer RJ, Friel EN, Souleyre EJF, Bolitho K, Thodey K, Ledger S, et al. A genomics approach reveals that aroma production in apple is controlled by ethylene predominantly at the final step in each biosynthetic pathway. Plant Physiol. 2007;144(4):1899-912. 
7. Pech JC, Bouzayen M, Latché A. Climacteric fruit ripening: Ethylenedependent and independent regulation of ripening pathways in melon fruit. Plant Sci. 2008;175(1-2):114-20.

8. Atkinson RG, Gunaseelan K, Wang MY, Luo L, Wang T, Norling CL, et al. Dissecting the role of climacteric ethylene in kiwifruit (Actinidia chinensis) ripening using a 1-aminocyclopropane-1-carboxylic acid oxidase knockdown line. J Exp Bot. 2011;62(11):3821-35.

9. Chang C, Kwok SF, Bleecker AB, Meyerowitz EM. Arabidopsis ethyleneresponse gene Etr1 - similarity of product to 2-component regulators. Science. 1993;262(5133):539-44.

10. Gao ZY, Chen YF, Randlett MD, Zhao XC, Findell JL, Kieber JJ, et al. Localization of the Raf-like kinase CTR1 to the endoplasmic reticulum of Arabidopsis through participation in ethylene receptor signaling complexes. J Biol Chem. 2003;278(36):34725-32.

11. Gao Z, Wen C-K, Binder BM, Chen Y-F, Chang J, Chiang Y-H, et al. Heteromeric interactions among ethylene receptors mediate signaling in arabidopsis. J Biol Chem. 2008;283(35):23801-10.

12. Grefen C, Städele K, Ružicka K, Obrdlik P, Harter K, Horák J. Subcellular localization and in vivo interactions of the Arabidopsis thaliana ethylene receptor family members. Mol Plant. 2008; (2):308-20.

13. Ju C, Chang C. Mechanistic insights in ethylene perception and signal transduction. Plant Physiol. 2015;169(1):85-95.

14. Manning $\mathrm{K}$, Tor M, Poole M, Hong $Y$, Thompson A, King G, et al. A naturally occurring epigenetic mutation in a gene encoding an SBP-box transcription factor inhibits tomato fruit ripening. Nat Genet. 2006;38:948-52.

15. Karlova R, Rosin F, Busscher-Lange J, Parapunova V, Do P, Fernie A, et al. Transcriptome and metabolite profiling show that APETALA2a is a major regulator of tomato fruit ripening. Plant Cell. 2011;23:923-41.

16. Chung M, Vrebalov J, Alba R, Lee J, McQuinn R, Chung J, et al. A tomato (Solanum lycopersicum) APETALA2/ERF gene, SIAP2a, is a negative regulato of fruit ripening. Plant J. 2010;64:936-47.

17. Vrebalov J, Ruezinsky D, Padmanabhan V, White R, Medrano D, Drake R, et al. A MADS-box gene necessary for fruit ripening at the tomato ripeninginhibitor (Rin) locus. Science. 2002;296:343-6.

18. Seymour G, Ryder C, Cevik V, Hammond J, Popovich A, King G, et al. A SEPALLATA gene is involved in the development and ripening of strawberry (Fragaria $x$ ananassa Duch.) fruit, a non-climacteric tissue. J Exp Bot. 2011;62:1179-88.

19. Ireland HS, Yao JL, Tomes S, Sutherland PW, Nieuwenhuizen N, Gunaseelan $K$, et al. Apple SEPALLATA1/2-like genes control fruit flesh development and ripening. Plant J. 2013;73(6):1044-56.

20. Mellway RD, Lund ST. Interaction analysis of grapevine MIKCc-type MADS transcription factors and heterologous expression of putative véraison regulators in tomato. J Plant Physiol. 2013;170(16):1424-33.

21. Bemer M, Karlova R, Ballester A, Tikunov Y, Bovy A, Wolters-Arts M, et al. The tomato FRUITFULL homologs TDR4/FUL1 and MBP7/FUL2 regulate ethylene-independent aspects of fruit ripening. Plant Cell. 2012;24:4437-51.

22. Itkin M, Seybold H, Breitel D, Rogachev I, Meir S, Aharoni A. TOMATO AGAMOUS-LIKE 1 is a component of the fruit ripening regulatory network. Plant J. 2009;60:1081-95.

23. Vrebalov J, Pan I, Arroyo A. Fleshy fruit expansion and ripening are regulated by the tomato SHATTERPROOF gene TAGL1. Plant Cell. 2009;21:3041-62.

24. Daminato M, Guzzo F, Casadoro G. A SHATTERPROOF-like gene controls ripening in non-climacteric strawberries, and auxin and abscisic acid antagonistically affect its expression. J Exp Bot. 2013;64(12):3775-86.

25. Fujisawa M, Nakano T, Ito Y. Identification of potential target genes for the tomato fruit-ripening regulator RIN by chromatin immunoprecipitation. BMC Plant Biol. 2011;11:26-40

26. Martel C, Vrebalov J, Tafelmeyer P, Giovannoni JJ. The tomato MADS-Box transcription factor RIPENING INHIBITOR interacts with promoters involved in numerous ripening processes in a COLORLESS NONRIPENING-dependent manner. Plant Physiol. 2011;157(3):1568-79.

27. Roy Choudhury S, Roy S, Nag A, Singh SK, Sengupta DN. Characterization of an AGAMOUS-like MADS box protein, a probable constituent of flowering and fruit ripening regulatory system in Banana. PLoS One. 2012;7(9):e44361.

28. Fujisawa M, Shima Y, Nakagawa H, Kitagawa M, Kimbara J, Nakano T, et al. Transcriptional regulation of fruit ripening by tomato FRUITFULL homologs and associated MADS box proteins. Plant Cell. 2014;26(1):89-101.

29. Fujisawa M, Nakano T, Shima Y, Ito Y. A large-scale identification of direct targets of the tomato MADS box transcription factor RIPENING INHIBITOR reveals the regulation of fruit ripening. Plant Cell. 2013;25(2):371-86.
30. Schroder R, Atkinson RG. Kiwifruit cell walls: towards an understanding of softening? N Z J Forestry Sci. 2006;36(1):112-29.

31. Pilkington SM, Montefiori M, Galer AL, Emery RJN, Allan AC, Jameson PE. Endogenous cytokinin in developing kiwifruit is implicated in maintaining fruit flesh chlorophyll levels. Ann Bot. 2013;112(1):57-68.

32. Burdon J, Pidakala P, Martin P, McAtee PA, Boldingh HL, Hall A, et al. Postharvest performance of the yellow-fleshed 'Hort16A' kiwifruit in relation to fruit maturation. Postharvest Biol Technol. 2014;92:98-106.

33. Richardson AC, Boldingh $\mathrm{HL}$, McAtee PA, Gunaseelan $\mathrm{K}$, Luo Z, Atkinson RG, et al. Fruit development of the diploid kiwifruit, Actinidia chinensis 'Hort16A' BMC Plant Biol. 2011;11:182.

34. Günther CS, Matich AJ, Marsh KB, Nicolau L. (Methylsulfanyl)alkanoate ester biosynthesis in Actinidia chinensis kiwifruit and changes during cold storage. Phytochemistry. 2010;71(7):742-50.

35. Nieuwenhuizen NJ, Chen X, Wang MY, Matich AJ, Perez RL, Allan AC, et al. Natural variation in monoterpene synthesis in kiwifruit: transcriptional regulation of terpene synthases by NAC and ETHYLENE-INSENSITIVE3-Like transcription factors. Plant Physiol. 2015;167(4):1243-58.

36. Burdon J, Lallu N. Kiwifruit (Actinidia spp.). Cambridge, UK: Woodhead Publishing; 2011.

37. Kim H, Hewett E, Lallu N. The role of ethylene in kiwifruit softening. Acta Horticulturae (ISHS). 1999;498:255-62.

38. Lallu N, Searle AN, Macrae EA. An investigation of ripening and handling strategies for early season kiwifruit (Actinidia deliciosa cv Hayward). J Sci Food Agric. 1989:47(4):387-400.

39. Regiroli G, Vriends P. SmartFreshSM (1-Methylcyclopropene) benifits for kiwifruit. Acta Hort. 2007;753:745-54.

40. Antunes M. The role of ethylene in kiwifruit ripening and senescence. Stewart Postharvest Rev. 2007;3(2):1-8.

41. Kader AA. Biology and technology: an overview. Postharvest Technol Horticultural Crops. 2002;3311:39-48.

42. Crowhurst R, Gleave A, MacRae E, Ampomah-Dwamena C, Atkinson R, Beuning $L$, et al. Analysis of expressed sequence tags from Actinidia: applications of a cross species EST database for gene discovery in the areas of flavor, health, color and ripening. BMC Genomics. 2008:9(1):351.

43. Fraser L, Tsang G, Datson P, De Silva HN, Harvey C, Gill G, et al. A gene-rich linkage map in the dioecious species Actinidia chinensis (kiwifruit) reveals putative X/Y sex-determining chromosomes. BMC Genomics. 2009;10(1):102.

44. Oliveira M, Barroso J, Martins M, Pais M. Genetic transformation in Actinidia deliciosa (Kiwifruit). In: Plant Protoplasts and Genetic Engineering V. Berlin Heidelberg: Springer; 1994. p 193-214.

45. Yin X-R, Chen K-S, Allan AC, Wu R-m, Zhang B, Lallu N, et al. Ethyleneinduced modulation of genes associated with the ethylene signalling pathway in ripening kiwifruit. J Exp Bot. 2008;59(8):2097-108.

46. Whittaker D, Smith G, Gardner R. Expression of ethylene biosynthetic genes in Actinidia chinensis fruit. Plant Mol Biol. 1997;34(1):45-55.

47. Yin X-R, Allan AC, Chen K-s, Ferguson IB. Kiwifruit ElL and ERF genes involved in regulating fruit ripening. Plant Physiol. 2010;153(3):1280-92.

48. Huang S, Ding J, Deng D, Tang W, Sun H, Liu D, et al. Draft genome of the kiwifruit Actinidia chinensis. Nat Commun. 2013;4:2640.

49. Varkonyi-Gasic E, Moss S, Voogd C, Wu R, Lough R, Wang Y-Y, et al. Identification and characterization of flowering genes in kiwifruit: sequence conservation and role in kiwifruit flower development. BMC Plant Biol. 2011;11(1):72.

50. Ito Y, Kitagawa M, Ihashi N, Yabe K, Kimbara J, Yasuda J, et al. DNA-binding specificity, transcriptional activation potential, and the rin mutation effect for the tomato fruit-ripening regulator RIN. Plant J. 2008;55(2):212-23.

51. Kosugi S, Ohashi Y. Cloning and DNA-binding properties of a tobacco Ethylene-Insensitive3 (EIN3) homolog. Nucleic Acids Res. 2000;28(4):960-7.

52. Hellens RP, Allan AC, Friel EN, Bolitho K, Grafton K, Templeton MD, et al. Transient expression vectors for functional genomics, quantification of promoter activity and RNA silencing in plants. Plant Methods. 2005;1(1):13.

53. Montefiori M, Espley RV, Stevenson D, Cooney J, Datson PM, Saiz A, et al. Identification and characterisation of F3GT1 and F3GGT1, two glycosyltransferases responsible for anthocyanin biosynthesis in red-fleshed kiwifruit (Actinidia chinensis). Plant J. 2011;65(1):106-18.

54. Garcia CV, Quek S-Y, Stevenson RJ, Winz RA. Characterisation of bound volatile compounds of a low flavour kiwifruit species: Actinidia eriantha. Food Chem. 2012;134(2):655-61.

55. Elitzur T, Vrebalov J, Giovannoni JJ, Goldschmidt EE, Friedman H. The regulation of MADS-box gene expression during ripening of banana and their regulatory interaction with ethylene. J Exp Bot. 2010;61(5):1523-35. 
56. Alba R, Payton P, Fei ZJ, McQuinn R, Debbie P, Martin GB, et al. Transcriptome and selected metabolite analyses reveal multiple points of ethylene control during tomato fruit development. Plant Cell. 2005;17(11):2954-65.

57. Pilati S, Perazzolli M, Malossini A, Cestaro A, Demattè L, Fontana P, et al. Genome-wide transcriptional analysis of grapevine berry ripening reveals a set of genes similarly modulated during three seasons and the occurrence of an oxidative burst at veraison. BMC Genomics. 2007;8(1):428.

58. Busi M, Bustamante C, D'Angelo C, Hidalgo-Cuevas M, Boggio S, Valle E, et al. MADS-box genes expressed during tomato seed and fruit development Plant Mol Biol. 2003;52:801-15.

59. Johnston JW, Gunaseelan K, Pidakala P, Wang M, Schaffer RJ. Co-ordination of early and late ripening events in apples is regulated through differential sensitivities to ethylene. J Exp Bot. 2009;60(9):2689-99.

60. Ireland HS, Gunaseelan K, Muddumage R, Tacken EJ, Putterill J, Johnston JW, et al. Ethylene regulates apple (Malus $x$ domestica) fruit softening through a dose-by-time dependent mechanism and through differential sensitivities and dependencies of cell wall-modifying genes. Plant Cell Physiol. 2014; 55(5):1005-16. doi:10.1093/pcp/pcu034.

61. Paul V, Pandey R, Srivastava GC. The fading distinctions between classical patterns of ripening in climacteric and non-climacteric fruit and the ubiquity of ethylene-An overview. J Food Sci Technol. 2012;49(1):1-21.

62. Chang S, Puryear J, Cairney J. A simple and efficient method for isolating RNA from pine trees. Plant Mol Biol Rep. 1993;11(2):113-6.

63. Bulley SM, Rassam M, Hoser D, Otto W, Schunemann N, Wright M, et al. Gene expression studies in kiwifruit and gene over-expression in Arabidopsis indicates that GDP-L-galactose guanyltransferase is a major control point of vitamin C biosynthesis. J Exp Bot. 2009;60(3):765-78.

\section{Submit your next manuscript to BioMed Central and we will help you at every step:}

- We accept pre-submission inquiries

- Our selector tool helps you to find the most relevant journal

- We provide round the clock customer support

- Convenient online submission

- Thorough peer review

- Inclusion in PubMed and all major indexing services

- Maximum visibility for your research

Submit your manuscript at www.biomedcentral.com/submit 